\title{
Isolation of Filamentous Fungi Species Contaminating Some Nigerian Food Commodities
}

\author{
Mary Augustina Egbuta ${ }^{1,2}$, Mulunda Mwanza ${ }^{1,2}$, Patrick Berka Njobeh², Judith Zanele Phoku' ${ }^{2}$, \\ Cynthia Adaku Chilaka ${ }^{2} \&$ Micheal Francis Dutton ${ }^{2}$ \\ ${ }^{1}$ Faculty of Agriculture, Science and Technology, North-West University, Mafikeng campus, South Africa \\ ${ }^{2}$ Food, Environment and Health Research Group, Faculty of Health Sciences, University of Johannesburg, \\ Doornfontein campus, South Africa \\ Correspondence: Mary Augustina Egbuta, Faculty of Agriculture, Science and Technology, North-West \\ University, Mafikeng campus, South Africa. Tel: 27-79-335-3366. E-mail: donmartinni@yahoo.com
}

Received: August 24, 2014 Accepted: October 10, 2014 Online Published: October 15, 2014

doi:10.5539/jfr.v4n1p38 URL: http://dx.doi.org/10.5539/jfr.v4n1p38

\begin{abstract}
Samples of maize, rice, cocoa and cocoa-based powder beverage) collected from different stores and markets in south-western Nigeria were screened for filamentous fungi contamination using conventional and molecular methods. Samples were cultured aseptically on potato dextrose agar (PDA), ohio agricultural experimental agar (OEASA), Malt Extract Agar (MEA) and Czapek Yeast Agar (CYA) prior to fungi isolation. Conventional methods comprising of macroscopic and microscopic evaluation of isolated fungi species were implemented in the analysis for identification of fungi species. Molecular method of identification involved DNA extraction, Polymerase chain Reaction (PCR) using ITS-1/ITS-4 primer pair and nucleotide sequencing. Results obtained indicated a range of filamentous fungi genus including Aspergillus, Penicillium, Fusarium, Alternaria, Cladosporium and Rhizopus contaminating the food commodities with Aspergillus and Penicillium species dominating most of the samples. High incidences were recorded for Aspergillus flavus, Aspergillus niger and Aspergillus fumigatus in most of the samples screened. The occurrence of these filamentous fungal species pose a reason for concern as most of these fungal species are known producers of toxic substances. This study was carried out to contribute to mycological screening of different Nigerian food commodities for a variety of filamentous fungi species.
\end{abstract}

Keywords: Aspergillus, filamentous fungi, Fusarium, food, Nigeria, Penicillium

\section{Introduction}

Filamentous fungi Aspergillus, Penicillium, Fusarium, Alternaria, Acremonium, Cladosporium and Curvularia are common micro-organisms in the environment found in the soil, air and contaminated food (Gołofit-Szymczak \& Górny, 2010; Pitt \& Hocking, 1997) due to their ubiquitous nature and because fungi can grow on any substrate under favourable conditions (Klein \& Paschke, 2004). Filamentous fungi are also known producers of secondary metabolites mycotoxins which have been investigated to have adverse health effects on both humans and animals when exposed to them (Meerdink, 2002; Muri, van der Voet, Boon, van Klaveren, \& Brüschweiler, 2009; Wagacha \& Muthomi, 2008). Aflatoxin B1 produced by A. flavus and A. parasiticus has been classified by the International Agency for Research on Cancer (IARC) as a Group 1 carcinogen and has been reported as one of the aetiologies of liver cancer (IARC, 2002, 2012).

Nigeria being the most populous nation in Africa with a population of over 130 million people has its domestic economy dominated by agriculture, which accounts for about $40 \%$ of the Gross Domestic Product (GDP) and two-thirds of the labour force. Agriculture supplies food, raw materials and generates household income for the majority of the people especially in the rural areas. Farming is often of the subsistence variety, characterized by simple tools and shifting cultivation as well as improper methods of storage and transportation of agricultural products. Large scale agriculture is not so common with few large scale farmers in the country. These small farms produce about $80 \%$ of the total food consumed (Akande, 2010). 
Agricultural products of Nigeria can be divided into two main groups: food crops, produced for home consumption and export crops. Subsistence food crops include sorghum, maize, yam, cassava, rice and millet whereas, cash crops consist of palm kernel, cotton, cocoa, rubber and groundnuts. Most of these agricultural products are sometimes processed into different types of food for consumption. An example is the preparation of "Ogi" and "pop corn" from maize and "fufu" from cassava. Agricultural products are usually cultivated by seasons and stored for availability all year round. As a result of the simple method of cultivation and improper storage of these agricultural products, there is the tendency for the agricultural products to be contaminated with fungi and mycotoxins.

Apart from being one of the important sources of revenue for Nigeria, cocoa is a raw material for the production of a range of food commodities such as chocolates, sweets, coffee, cocoa powder, cocoa beverages, biscuits etc. (Sánchez-Hervás, Gil, Bisbal, Ramón, \& Martínez-Culebras, 2008). Cultivated mainly in western and central Africa (Cocoa-growing; Cocoastory) as well as some parts of South America and Europe (Amézqueta, González-Peñas, Murillo, \& López de Cerain, 2005; Ardhana \& Fleet, 2003; Brera et al., 2011; Copetti, Iamanaka, Pereira, Fungaro, \& Taniwaki, 2011), cocoa has become a very essential part of human lives because of the forms in which it is consumed. Rice is also considered a staple food in Nigeria because it is consumed in most households on a daily basis with the consumption of rice growing annually by $10 \%$ since the $1970 \mathrm{~s}$ (Akande, 2010). Maize is consumed as well in many households in Nigeria in various forms.

With the growing awareness of food safety worldwide, it is of essence that the safety and quality of food consumed on a daily basis in Nigeria be continually evaluated. This study was therefore conducted in other to determine the occurrence and population of filamentous fungi species in different food commodities from Nigeria in order to assess the possible health dangers consumers are exposed to.

\section{Materials and Methods}

All chemicals and reagents used in this study were at least of analytical grade, unless otherwise specified.

\subsection{Sampling and Sample Preparation}

One hundred and forty-four (144) samples consisting of maize (39), rice (41), cocoa seeds (17), processed cocoa (22) and cocoa-based powder beverage each weighing about $200 \mathrm{~g}$ were collected from different stores and markets in south-west and south-east Nigeria. Representative samples were collected in plastic bags and sealed for transportation to the Food, Environment and Health Research laboratory, University of Johannesburg, South Africa following all necessary custom duty protocols. All samples collected were destined for human consumption. On arrival at the laboratory, seed samples were ground using a laboratory mill (IKA M20, Merck, Darmstadt, Germany) for further analysis.

\subsection{Mycological Screening of Samples}

To determine fungal population in samples following the method of (Njobeh, Dutton, Koch, Chuturgoon, Stoev, \& Seifert, 2009) with slight modifications, potato dextrose agar (PDA) and ohio agricultural experimental agar (OAESA) were used. Ohio agricultural experimental agar was prepared by dissolving glucose $(5 \mathrm{~g})$, yeast extract $(2 \mathrm{~g})$, sodium nitrite $(1 \mathrm{~g})$, magnesium sulphate $(0.5 \mathrm{~g})$, di-potassium hydrogen phosphate $(1 \mathrm{~g})$, oxbile $(1 \mathrm{~g})$ sodium propionate $(1 \mathrm{~g})$ and Nutrient agar $(20 \mathrm{~g})$ in $900 \mathrm{ml}$ distilled water and was made up to 1 litre. Potato dextrose agar was prepared by dissolving PDA (39 g) in 1 litre of distilled water. Both agar were autoclaved at $121{ }^{\circ} \mathrm{C}$ and $15 \mathrm{psi}$ for $15 \mathrm{mins}$, cooled in a $50{ }^{\circ} \mathrm{C}$ water bath and eight $(8)$ millilitre $(\mathrm{ml})$ each of $1 \%$ chloramphenicol/ $1 \%$ streptomycin antibiotic solution added to agar before pouring into sterile petri dishes.

One (1) gram of each sample was weighed after thorough mixing using sterile weighing boats and transferred to sterile test-tubes containing $9 \mathrm{ml}$ sterile ringer's solution, vortexed and serially diluted to make six dilutions $\left(10^{-6}\right)$ per sample. Ringers solution was prepared by dissolving two ringers tablets in 1 litre of distilled water and autoclaved at $121{ }^{\circ} \mathrm{C}$ and $15 \mathrm{psi}$ for $15 \mathrm{mins}$. One $\mathrm{ml}$ of sample was pipetted from each test tube unto PDA and OAESA and incubated for $4-7$ days at $25{ }^{\circ} \mathrm{C}$. Fungal colonies were determined using a colony counter and number of fungal colonies per gram of sample calculated and expressed in colony forming units per gram of sample $(\mathrm{Cfu} / \mathrm{g})$ as:

$$
\mathrm{Cfu} / \mathrm{g}=\frac{\text { Number of colonies } \mathrm{x} \text { reciprocal of the dilution factor }}{\text { Plating volume }(1 \mathrm{ml})}
$$




\subsection{Fungal Isolation From Sample Cultures}

Isolation of fungi was done using PDA, malt extract agar (MEA) and (CYA). Czapek yeast agar was prepared by dissolving di-potassium hydrogen phosphate $(1 \mathrm{~g})$, yeast extract $(5 \mathrm{~g})$, sucrose $(30 \mathrm{~g})$, agar powder $(15 \mathrm{~g})$ and czapek concentrate $(10 \mathrm{ml})$ in $1 \mathrm{~L}$ of distilled water. Malt extract agar was prepared by dissolving 50 grams of malt extract in 1 litre of distilled water. The different agar were autoclaved at $121{ }^{\circ} \mathrm{C}$ and $15 \mathrm{psi}$ for 15 mins, cooled to $50{ }^{\circ} \mathrm{C}$ using a water bath and poured into sterile petri dishes. Fungal colonies were isolated using a sterile wire loop onto agar in sterile petri dishes and incubated at $25{ }^{\circ} \mathrm{C}$ for 7 days for macroscopic and microscopic identification.

\subsection{Molecular Identification of Fungal Identification}

\subsubsection{DNA Extraction}

Deoxyribonuleotide (DNA) extraction was done using a Fungal/Bacterial DNA extraction kit (Zymo Research Corporation, Southern California, USA). Fungal isolates were cultured on PDA at $25{ }^{\circ} \mathrm{C}$ for $2-4$ days, mycelium freeze-dried and about $60 \mathrm{mg}$ of mycelium mixed with $750 \mu \mathrm{l}$ of DNA lysing solution in a $1.5 \mathrm{ml}$ ZR Bashing BeadTM lysis tube. This was followed by lysing of the fungal cells using a disruptor genie bead beater fitted with a $2 \mathrm{ml}$ tube holder assembly (Scientific industries inc., USA) and processed at maximum speed for 5 mins. Lysed samples were centrifuged at 10,000 rpm for 1 minute and supernatant transferred to a zymo-spin IV spin filter in a collection tube and centrifuged at 7,000 rpm for 1 minute. The filtrate was added to fungal DNA binding buffer and centrifuged in a Zymo-spin IIc column placed in a collection tube at 10,000 $\times \mathrm{g}$ for 1 minute. This was followed by washing of DNA in the column using a pre-wash buffer and wash buffer. Fungal DNA was finally eluted with $100 \mu \mathrm{l}$ of DNA elution buffer and centrifuged at $10,000 \times \mathrm{g}$ for 30 mins. Eluted DNA was stored at $-20{ }^{\circ} \mathrm{C}$ for further analysis.

\subsubsection{Agarose Gel DNA Electrophoresis}

Deoxyribonucleotide acid (DNA) gel electrophoresis was done by preparation of $2 \%$ agarose gel ( $2 \mathrm{~g}$ of agarose (Fermentas Life Science, Lithuania) in $98 \mathrm{ml}$ 1x TAE buffer (Fermentas Life Science, Lithuania) which was boiled in a microwave and cooled to approximately $60{ }^{\circ} \mathrm{C}$. This was followed by the addition of seven (7) $\mathrm{ml}$ of ethidium bromide (Sigma-Aldrich, ST Louis, MO, USA) to the agarose solution. The agarose solution was poured into a casting chamber (Bio-Rad Laboratories, California, USA) and allowed to set. Casting chamber containing the solid agarose was further inserted into the electrophoresis tank (Bio-Rad Laboratories, California, USA) filled with $1 \times$ TAE buffer. Fungal DNA $(5 \mu \mathrm{l})$ was mixed with $3 \mu \mathrm{l}$ of $6 \mathrm{X}$ orange loading dye (Fermentas Life Science, Lithuania) and loaded into the wells. The chamber was closed and run at $450 \mathrm{~V}$ and $70 \mathrm{~mA}$ for 30 minutes and DNA viewed using the ChemiDoc gel imaging system (Bio-Rad Laboratories, California, USA).

\subsubsection{Polymerase Chain Reaction (PCR)}

Amplification of extracted DNA was done using ITS-1/ITS-4 primer pairs for forward and reverse amplification as described by (O'Donnell \& Cigelnik, 1997). Primers were designed in conserved 5' and 3' regions which resulted in the amplification of a $450 \mathrm{bp}$ elongation factor product. Synthesis of primers was done at a $0.01 \mu \mathrm{M}$ scale and purified using reverse-phase cartridge purification (Inqaba Biotechnical Industries (Pty) Ltd, South Africa).

The final PCR solution for each sample consisted of $25 \mu \mathrm{l}$ of $2 \times$ PCR master mix, $1 \mu \mathrm{l}$ of each $2 \mu \mathrm{M}$ primer, $1 \mu \mathrm{l}$ of DNA (final concentration of $10 \mu \mathrm{M}$ ), and constituted to a final volume of $50 \mu \mathrm{l}$ with nuclease free water. Polymerase chain reaction was performed using an eppendorf 96-well Thermocycler (Eppendorf, USA) and cycling conditions set as: Pre-dwelling at $95^{\circ} \mathrm{C}$ for 3 mins, 35 cycles denaturation at $95{ }^{\circ} \mathrm{C}$ for 1 min, annealing at $58^{\circ} \mathrm{C}$ for 45 secs, extension at $72{ }^{\circ} \mathrm{C}$ for 1 min 30 seconds, post-dwelling at $72{ }^{\circ} \mathrm{C}$ for 10 minutes and held at 4 ${ }^{\circ} \mathrm{C}$ until samples were retrieved.

\subsubsection{Sequencing of PCR Products and Data Analysis}

Products from PCR analysis were cleaned using shrimp alkaline phosphatase and E. coli exonuclease I (Fermentas Life Sciences, Lithuania). Agarose Gel electrophoresis was done as initially described to confirm DNA amplification using a DNA ladder (marker) (Fermentas Life Science, Lithuania). Automated DNA sequencing was performed at Inqaba Biotechnical Industries (Pty) Ltd (Pretoria, RSA) using the SpectruMedix model SCE 2410 automated DNA sequencer (SpectruMedix, State College, PA). Sequencing reaction mixture (prepared by Inqaba Biotechnical Industries (Pty) Ltd, South Africa) included the ABI BigDye Terminator Cycle Sequencing kit version 3.1 dye (Applied Biosystems, Foster City, CA) and the same primers used in the original PCR reaction. For analysis of fungal sequences, reference sequences for the TEF $1 \alpha$ coding region were used 
and these sequences, in FASTA format were obtained from EMBL databases (National Center for Biotechnology Information, U.S. National Institute of Health, Bethesda, MD).

\section{Results}

Mycological analysis in this study showed a wide range of filamentous fungal species belonging to the genera Aspergillus, Penicillium and Fusarium contaminating food commodities with varying colony forming units (Cfu) indicated in Table 1. Cocoa and cocoa- based powder beverages were contaminated mainly with a range of Aspergillus species dominated by the prevalence of Aspergillus flavus (82.4\%), Aspergillus fumigatus (76.5\%), Aspergillus niger (82.4\%), Aspergillus parasiticus (54.6\%) and Aspergillus ochraceus (52.9\%) with lesser incidences of Penicillium and Fusarium species.

Table 1. Colony formation unit per gram $(\mathrm{Cfu} / \mathrm{g})$ of fungal species recovered per sample from rice, maize, unprocessed cocoa, processed cocoa and cocoa-based powder beverages

\section{$\mathrm{Cfu} / \mathrm{g}$ of fungi in different commodities}

\begin{tabular}{|c|c|c|c|c|c|}
\hline Fungi & Rice & Maize & $\begin{array}{c}\text { Cocoa } \\
\text { Unprocessed }\end{array}$ & $\begin{array}{c}\text { Cocoa } \\
\text { Processed }\end{array}$ & $\begin{array}{c}\text { Cocoa } \\
\text { Powder } \\
\text { Beverages }\end{array}$ \\
\hline Alternaria & $12.3 \times 10^{4}$ & - & - & - & - \\
\hline Aspergillus auricomus & $6.2 \times 10^{3}$ & - & - & - & - \\
\hline Aspergillus awamori & $4.6 \times 10^{5}$ & - & - & - & - \\
\hline Aspergillus caespitosus & - & - & - & $3.0 \times 10^{4}$ & $5.8 \times 10^{4}$ \\
\hline Aspergillus candidus & $6.2 \times 10^{4}$ & $6.2 \times 10^{5}$ & - & - & - \\
\hline Aspergillus carbonarius & $14.1 \times 10^{5}$ & - & $6.8 \times 10^{6}$ & $14.3 \times 10^{5}$ & - \\
\hline Aspergillus flavus & $39.7 \times 10^{6}$ & $25.4 \times 10^{5}$ & $20.9 \times 10^{6}$ & $27.6 \times 10^{6}$ & $7.2 \times 10^{5}$ \\
\hline Aspergillus foetidus & $3.8 \times 10^{5}$ & - & - & - & - \\
\hline Aspergillus fumigatus & $22.3 \times 10^{6}$ & $16.7 \times 10^{6}$ & $18.6 \times 10^{6}$ & $32.1 \times 10^{6}$ & $10.7 \times 10^{4}$ \\
\hline Aspergillus japonicus & - & - & $4.2 \times 10^{6}$ & - & - \\
\hline Aspergillus melleus & - & - & - & - & - \\
\hline Aspergillus niger & $18.3 \times 10^{6}$ & $29.4 \times 10^{6}$ & $19.2 \times 10^{6}$ & $30.5 \times 10^{6}$ & - \\
\hline Aspergillus niveus & $3.6 \times 10^{4}$ & - & - & - & - \\
\hline Aspergillus ochraceus & - & - & $12.3 \times 10^{6}$ & - & - \\
\hline Aspergillus oryzae & $21.6 \times 10^{6}$ & $12.4 \times 10^{5}$ & - & $10.4 \times 10^{5}$ & - \\
\hline Aspergillus paradoxus & $8.4 \times 10^{5}$ & - & - & - & - \\
\hline Aspergillus parasiticus & - & $21.6 \times 10^{5}$ & $9.7 \times 10^{6}$ & $24.0 \times 10^{6}$ & $8.6 \times 10^{5}$ \\
\hline Aspergillus penicilliodes & $3.5 \times 10^{4}$ & - & - & - & - \\
\hline Aspergillus versicolor & - & - & - & $2.0 \times 10^{4}$ & - \\
\hline Cladosporium & $19.8 \times 10^{6}$ & $6.2 \times 10^{4}$ & - & - & $8.8 \times 10^{5}$ \\
\hline Emericella nidulans & - & - & - & $4.0 \times 10^{4}$ & - \\
\hline Fusarium & - & - & $5.1 \times 10^{5}$ & $6.5 \times 10^{4}$ & - \\
\hline Fusarium chlamydosporum & $5.4 \times 10^{4}$ & - & - & - & - \\
\hline Fusarium graminearum & $14.7 \times 10^{6}$ & $30.6 \times 10^{6}$ & - & - & - \\
\hline Fusarium oxysporum & $14.9 \times 10^{5}$ & $24.8 \times 10^{6}$ & - & - & - \\
\hline Fusarium proliferatum & $17.8 \times 10^{6}$ & $29.8 \times 10^{6}$ & - & - & - \\
\hline Fusarium sambucinum & $2.1 \times 10^{4}$ & - & - & - & - \\
\hline Fusarium semitectum & $7.2 \times 10^{4}$ & - & - & - & - \\
\hline
\end{tabular}


Fusarium solani

Fusarium sporotrichiodes

Fusarium subglutinans

Paecilomyces fulvus

Penicillium aethiopicum

Penicillium aurantiogriseum

Penicillium crustosum

Penicillium digitatum

Penicillium expansum

Penicillium hirsutum

Penicillium islandicum

Penicillium olsonii

Penicillium polonicum

Penicillium purpurogenum

Penicillium solitum

Penicillium thomii

Penicillium viridicatum

Rhizopus

$\begin{array}{ll}- & 21.3 \times 10^{4} \\ 17.8 \times 10^{6} & 18.6 \times 10^{5} \\ 13.2 \times 10^{5} & - \\ - & - \\ 1.7 \times 10^{4} & 18.7 \times 10^{5} \\ 1.7 \times 10^{4} & - \\ 2.2 \times 10^{3} & 17.7 \times 10^{6} \\ 3.6 \times 10^{4} & 24.8 \times 10^{6} \\ - & - \\ 15.3 \times 10^{6} & 22.5 \times 10^{6} \\ - & 15.9 \times 10^{5} \\ 16.8 \times 10^{6} & - \\ 2.4 \times 10^{4} & 13.8 \times 10^{5} \\ 6.2 \times 10^{4} & - \\ 8.7 \times 10^{5} & - \\ 11.7 \times 10^{5} & - \\ 2.3 \times 10^{4} & - \\ 11.8 \times 10^{5} & -\end{array}$

$$
6.3 \times 10^{4}
$$$$
5.4 \times 10^{4}
$$$$
-
$$$$
-
$$$$
-
$$$$
\text { . }
$$

$13.5 \times 10^{5}$
$4.7 \times 10^{4}$

$5.9 \times 10^{4}$

$6.3 \times 10^{4}$

\section{-}

Rice samples analysed showed a prevalence of different Aspergillus, Penicillium, Fusarium, Alternaria and Cladosporium species contaminating them with $A$. flavus and A. fumigatus dominating and having $65.9 \%$ and $53.7 \%$ incidences respectively. Maize samples were contaminated with fungal genera Aspergillus, Penicillium, Fusarium and Cladosporium with high incidences of $F$. verticillioides $(76.9 \%)$, A. fumigatus $(73.4 \%)$ and $A$. flavus $(66.7 \%)$. Incidences of filamentous fungi species illustrated in Table 2 indicated less contamination of cocoa-based powder beverages by the same fungi species which were contaminating cocoa seeds.

Table 2. Incidence (\%) of fungal species recovered from rice, maize, unprocessed cocoa, processed cocoa and cocoa-based powder beverages

Incidence $(\%)$ of fungi in different commodities

\begin{tabular}{|c|c|c|c|c|c|}
\hline Fungi & Rice & Maize & $\begin{array}{c}\text { Cocoa } \\
\text { Unprocessed }\end{array}$ & $\begin{array}{c}\text { Cocoa } \\
\text { Processed }\end{array}$ & $\begin{array}{c}\text { Cocoa } \\
\text { Powder } \\
\text { Beverages }\end{array}$ \\
\hline Alternaria & 12.2 & - & - & - & - \\
\hline Aspergillus auricomus & 7.3 & - & - & - & - \\
\hline Aspergillus awamori & 7.3 & - & - & - & - \\
\hline Aspergillus caespitosus & - & - & - & 4.6 & 8.0 \\
\hline Aspergillus candidus & 7.3 & 18.0 & - & - & - \\
\hline Aspergillus carbonarius & 17.1 & - & 29.4 & 18.2 & - \\
\hline Aspergillus flavus & 65.9 & 66.7 & 82.4 & 72.7 & 24.0 \\
\hline Aspergillus foetidus & 7.3 & - & - & - & - \\
\hline Aspergillus fumigatus & 53.7 & 73.4 & 76.5 & 40.9 & 16.0 \\
\hline Aspergillus japonicus & - & - & 11.8 & - & - \\
\hline Aspergillus melleus & - & - & - & - & - \\
\hline
\end{tabular}




\begin{tabular}{|c|c|c|c|c|c|}
\hline Aspergillus niger & 41.0 & 46.2 & 82.4 & 45.5 & - \\
\hline Aspergillus niveus & 2.4 & - & - & - & - \\
\hline Aspergillus ochraceus & - & - & 52.9 & - & - \\
\hline Aspergillus oryzae & 46.2 & 15.4 & - & 18.2 & - \\
\hline Aspergillus paradoxus & 9.8 & - & - & - & - \\
\hline Aspergillus parasiticus & - & 25.6 & 29.4 & 54.6 & 16.0 \\
\hline Aspergillus penicilliodes & 4.9 & - & - & - & - \\
\hline Aspergillus versicolor & & & & 4.6 & - \\
\hline Cladosporium & 22.0 & 12.8 & - & - & 32.0 \\
\hline Emericella nidulans & & & & 9.1 & - \\
\hline Fusarium & - & - & 17.6 & 9.1 & - \\
\hline Fusarium chlamydosporum & 4.9 & - & - & - & - \\
\hline Fusarium graminearum & 17.1 & 25.6 & - & - & - \\
\hline Fusarium oxysporum & 22.0 & 35.9 & - & - & - \\
\hline Fusarium proliferatum & 24.4 & 64.1 & - & - & - \\
\hline Fusarium sambucinum & 2.4 & - & - & - & - \\
\hline Fusarium semitectum & 9.8 & - & - & - & - \\
\hline Fusarium solani & - & 20.5 & - & - & - \\
\hline Fusarium sporotrichiodes & 19.5 & 25.6 & - & - & - \\
\hline Fusarium subglutinans & 17.1 & - & - & - & - \\
\hline Paecilomyces fulvus & - & - & 29.1 & - & 8.0 \\
\hline Penicillium aethiopicum & 4.9 & 10.3 & - & - & - \\
\hline Penicillium aurantiogriseum & 2.4 & - & 17.7 & - & - \\
\hline Penicillium crustosum & 4.9 & 20.5 & - & - & - \\
\hline Penicillium digitatum & 7.3 & 30.8 & - & - & - \\
\hline Penicillium expansum & - & - & - & - & 8.0 \\
\hline Penicillium hirsutum & 22.0 & 33.3 & - & - & 8.0 \\
\hline Penicillium islandicum & - & 15.4 & - & - & - \\
\hline Penicillium olsonii & 14.6 & - & - & - & - \\
\hline Penicillium polonicum & 4.9 & 15.4 & - & - & - \\
\hline Penicillium purpurogenum & 7.3 & - & - & - & - \\
\hline Penicillium solitum & 9.8 & - & - & - & - \\
\hline Penicillium thomii & 12.2 & - & - & - & - \\
\hline Penicillium viridicatum & 2.4 & - & - & - & - \\
\hline Rhizopus & 14.6 & - & 52.9 & 31.8 & 12.0 \\
\hline
\end{tabular}

A comparison of the fungal population of food commodities from the two collection areas (stores and markets) as indicated in (Figures 1-4) showed slight differences in rice and cocoa samples and remarkable differences in maize samples. This comparison was based on incidences of filamentous fungi contaminating food samples collected from stores and markets. Although rice samples from markets had higher incidences of Aspergillus, Penicillium and Fusarium, lower incidences were reported for Cladosporium and Alternaria species in rice samples from markets. Maize samples had higher incidences of Aspergillus and Penicillium species contaminating samples from stores compared to those from markets. Cocoa samples from both collection areas were contaminated by Aspergillus and Penicillium species while samples form stores were not contaminated by 
Fusarium species. Figure 4 also showed the non-occurrence of Fusarium and Alternaria species in cocoa-based powder beverage samples.

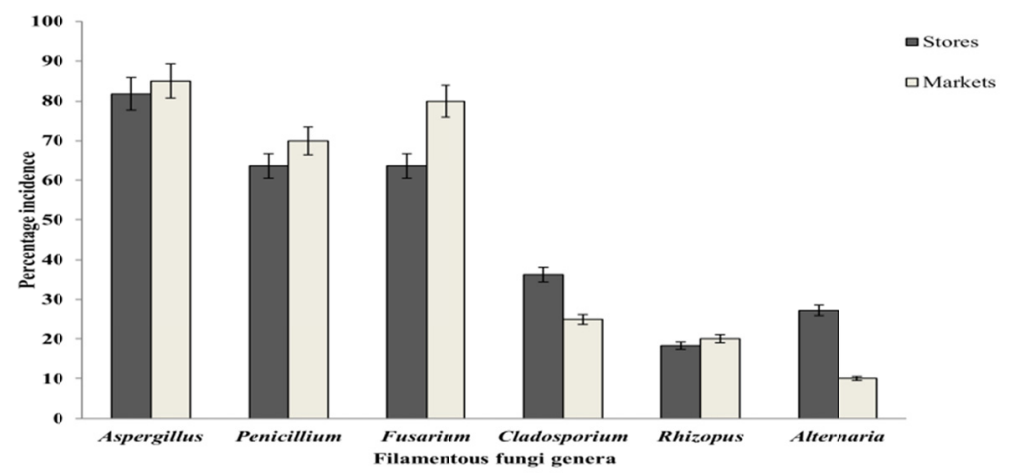

Figure 1. Incidence in percentage of different filamentous fungi genera contaminating rice samples from markets and stores

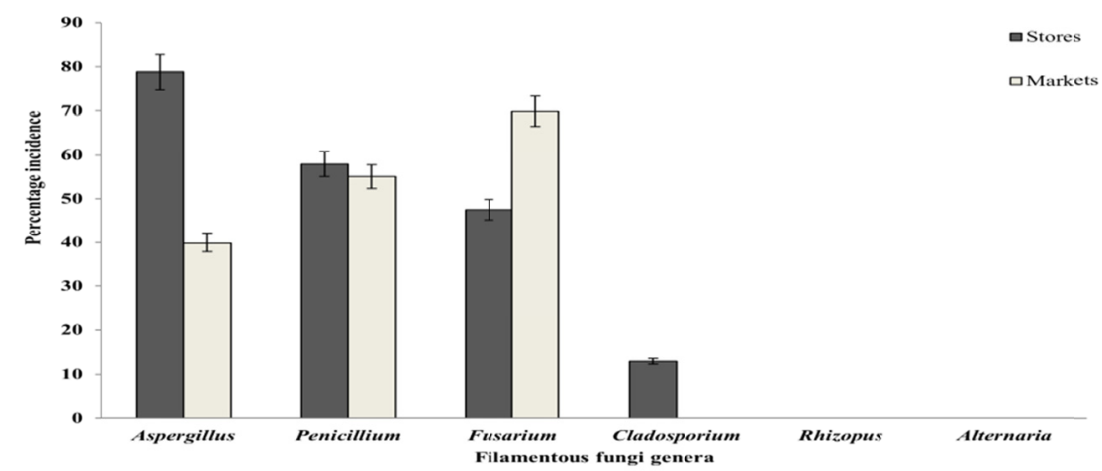

Figure 2. Incidence in percentage of different filamentous fungi genera contaminating maize samples from markets and stores

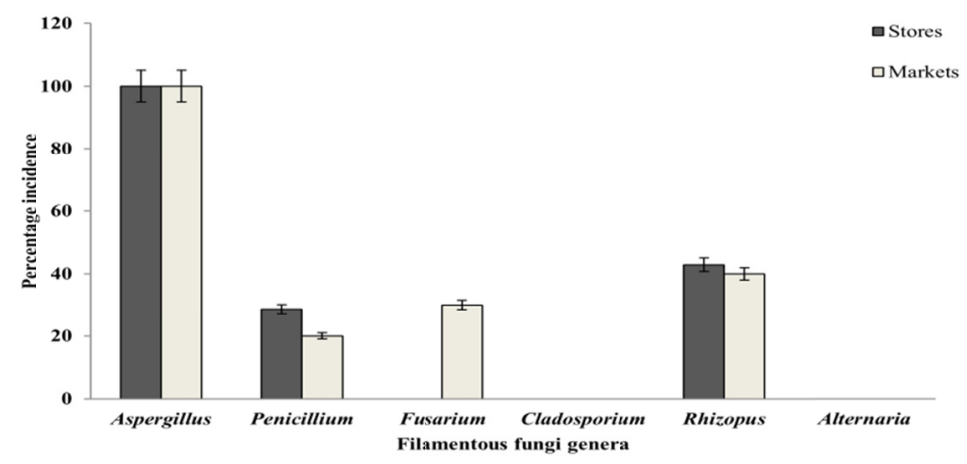

Figure 3. Incidence in percentage of different filamentous fungi genera contaminating cocoa samples from markets and stores 


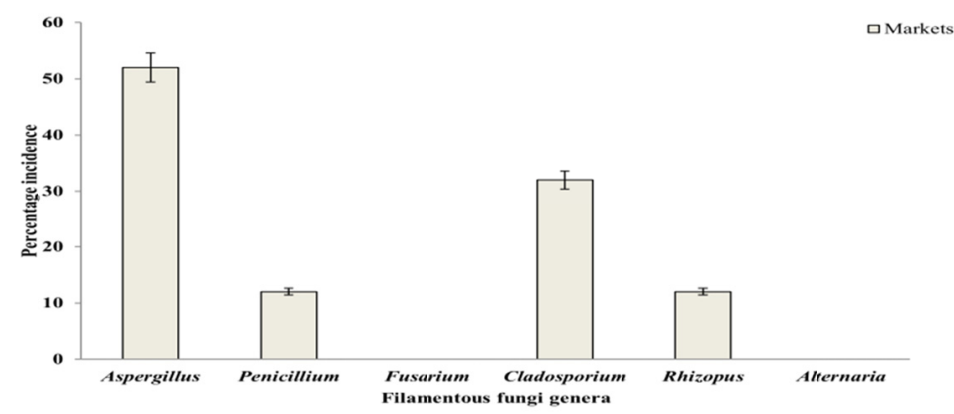

Figure 4. Incidence in percentage of different filamentous fungi genera contaminating cocoa-based beverage samples from markets and stores

\section{Discussion}

Fungal analysis in this study showed a prevalence of the genera Aspergillus, Penicillium and Fusarium in all samples of food commodity analysed. These fungal species are common mycotoxigenic fungi associated with the human food chain as a result of their prevalence in grains, nuts, seeds, fruits, tubers, grain-based products, etc (Kumar, Basu, \& Rajendran, 2008; Petzinger \& Weidenbach, 2002; Sánchez-Hervás, Gil, Bisbal, Ramón, \& Martínez-Culebras, 2008). Occurrences of some of these species of fungi have been reported in other agricultural and agricultural based products in Nigeria (Jonathan \& Esho, 2010; Makun et al., 2010; Makun, Gbodi, Akanya, Salako, \& Ogbadu, 2009).

Mycological screening of the different food commodities analyzed showed a variation of filamentous fungal genera contaminating them. Cocoa samples were contaminated mainly by fungal species belonging to the genera Aspergillus (100\%) and less by Rhizopus (42.9\%) and Fusarium (30\%). Aspergillus species such as A. niger, A. flavus, A. ochraceus, A. parasiticus and A. fumigatus were most prevalent in all cocoa samples. Also, incidences of fungi species of the mentioned genera were detected in processed cocoa samples; though higher incidences (indicated in Table 2) with high Cfu/g of samples were recorded in the cocoa seed samples in comparison to processed cocoa samples. This could be explained by incidences of $82.4 \%$ and $72.7 \%$ of A. flavus, $82.4 \%$ and $45.5 \%$ of $A$. niger, $76.5 \%$ and $40.9 \%$ of A. fumigatus, $52.9 \%$ and $31.8 \%$ of Rhizopus in cocoa seeds and processed cocoa samples respectively. Fungal contamination of cocoa samples can be attributed to post-harvest conditions such as storage and mode of transportation. Most of the storage houses in the collection areas were not properly ventilated and sanitized with cocoa seeds packed in old sacks and stacked one on top of the other. Also, transportation of most crops and food commodities in the collection areas is usually in open Lorries and trucks that are not always cleaned. Other reasons suggested for fungal contamination of cocoa samples could be climatic conditions (Wagacha \& Muthomi, 2008) which in the case of the collection areas was hot and humid.

The finding that fungal contamination in processed cocoa was less compared to cocoa seeds could be as a result of the process of drying, dehulling, milling and fermentation which have been reported to reduce fungal and mycotoxin occurrence in food commodities (Fandohan, Gnonlonfin, Hell, Marasas, \& Wingfield, 2005; Turner et al., 2005). Also, data from this study showed an increase in contamination by A. parasiticus in processed cocoa samples (54.6\%) in comparison to cocoa seed samples $(29.4 \%)$ which can be as a result of the storage practices, open air display of wares by sellers in the market and mode of transportation. Fungi species isolated from both categories of cocoa samples have been reported in other studies from different parts of the world (Brazil and Spain) to be associated with cocoa seeds and cocoa products (Copetti, Pereira, Iamanaka, Pitt, \& Taniwaki, 2010; de Magalhães, Sodré, Viscogliosi, \& Grenier-Loustalot, 2011; Sánchez-Hervás, Gil, Bisbal, Ramón, \& Martínez-Culebras, 2008) with specific reference to A. niger, A. ochraceus and A. flavus species as most occurring species. These species have been reported to be sources of mycotoxins in cocoa samples producing ochratoxin A (Mounjouenpou, Gueule, Fontana-Tachon, Guyot, Tondje, \& Guiraud, 2008) and aflatoxins in cocoa seeds and cocoa products.

Cocoa-based powder beverages were less contaminated by fungi species with reduced incidences of $A$. flavus (24\%), A. fumigatus (16\%) and A. parasiticus (16\%) in comparison to cocoa samples. There were also less values for colony formation of fungi species per unit gram of cocoa-based samples analysed which could be attributed to the processes involved in manufacturing of these cocoa-based powder beverages which include sinnowing, dehulling, washing, milling, roasting, pasteurisation and use of additives (Cocoastory). The 
prevalence of Aspergillus species in cocoa and cocoa-based samples analysed corresponds with the high occurrence of Aspergillus species in areas of high temperatures and humidity (Fassatiova, 1986) as regards to the climatic conditions of the collection areas (Nigeria). Also, the fact that Aspergillus species are commonly isolated from soil and indoor environments (Klich, 2002); and are the most frequently isolated fungi species from cocoa-based beverages in Nigeria (Oyetunji, 2006) corroborates results obtained from this study.

Maize samples analysed showed contamination by mainly Aspergillus, Fusarium, Penicillium species and less by Cladosporium species; with a prevalence of Aspergillus flavus (66.7\%), Aspergillus fumigatus (73.4\%), Fusarium verticillioides (76.9\%) and Fusarium proliferatum (64.1\%). Other species of less incidences found to occur included A.niger, F. graminearum, A. candidus, A. parasiticus, $F$. oxysporum and $P$. digitatum amongst others. This confirms several other reports from Nigeria in recent years which have shown high incidences of these fungi species in maize seeds from different parts of the country with special reference to A. flavus, A. parasiticus, A. niger, F. verticillioides and F. proliferatum (Adejumo, Hettwer, \& Karlovsky, 2007; Atehnkeng et al., 2008; Makun et al., 2010). Reports from other parts of Africa and the world also show high incidences of these fungal species aforementioned in maize seeds at different stages of cultivation/production with $F$. verticillioides commonly isolated from maize seeds in South Africa (Chilaka, De Kock, Phoku, Mwanza, Egbuta, \& Dutton, 2012; Dutton, 1996, 2003; Marasas, 2001; Sydenham, Thiel, Marasas, Shephard, van Schalkwyk, \& Koch, 1990). Fusarium verticillioides was also reported to contaminate maize and maize-based products in the Republic of Benin in West Africa (Fandohan, Gnonlonfin, Hell, Marasas, \& Wingfield, 2005) in combination with Aspergillus species and Penicillium species even at different harvest timings (Borgemeister et al., 1998). Studies by Adejumo, Hettwer, and Karlovsky (2007) also showed an incidence of $F$. verticillioides of $71 \%$ in maize from four different states in south-western Nigeria, followed by $F$. sporotrichioides $(64 \%)$ and $F$. graminearum $(32 \%)$.

Fungal species isolated from maize samples in this study are reported to be producers of major mycotoxins i.e., aflatoxins, ochratoxin A, fumonisins, zearalenone and deoxynivalenol; which are contributory causes of different forms of health implications in both man and animals (Chu \& Li, 1994; Dutton, \& Michael, 1996; Hussein \& Brasel, 2001). There was a difference in concentration in colony formation and fungal contamination in maize samples bought from the market compared to those collected from stores. Incidence of Aspergillus and Penicillium species was higher in maize samples collected from the store houses $(78.9 \%$ and $57.9 \%)$ in comparison to Fusarium species (47.4\%) whereas, Fusarium species (70\%) and Penicillium species (55\%) had higher incidences compared to Aspergillus species (40\%) in maize samples collected from the markets. This could be attributed to the report that Aspergillus and Penicillium species are storage fungi which contaminate most food commodities in storage (Pitt \& Hocking, 1997).

Rice samples screened for fungal contamination indicated a wide range of species belonging to the genera Aspergillus, Penicillium, Fusarium, Alternaria, Rhizopus and Cladosporium with A. flavus contaminating most of the samples (percentage incidence of 65.9\%). Samples were highly contaminated with Aspergillus species in comparison to other genera. The prevalence of Aspergillus species could be attributed to high temperatures (up to $30{ }^{\circ} \mathrm{C}$ and over) of the collection areas and improper storage practices. This is because rice is normally dried after harvesting prior to storage, but, inappropriate storage conditions could cause rice seeds to be suitable substrates for fungal growth (Reiter, Vouk, Bohm, \& Razzazi-Fazeli, 2010). Also, it has been reported that crops grown in cool climate areas are usually less contaminated with Aspergillus species than those in warmer climate areas due to the nature of the species that belong to the genus Aspergillus (Reiter, E., Zentek, \& Razzazi, 2009; Reiter, Vouk, Bohm, \& Razzazi-Fazeli, 2010). It is known that fungal contamination of rice usually occurs in two phases; crop developmental (pre-harvest) and contamination of mature grains (post-harvest) (Juliano, 2003; Usha, Patkar, Shetty, Kennedy, \& Lacey, 1993).

Data obtained from fungal analysis of rice showed a variation in fungal genera contaminating samples from the markets and stores. The variation in degree of fungal contamination could be attributed to conditions earlier mentioned of inappropriate storage conditions of high temperature and humidity. Reports from other studies in rice from northern Nigerian has shown contamination by Aspergillus species, Fusarium species, Penicillium species, Cladosporium species, Trichoderma and Rhizopus species (Makun, Hussaini Anthony, Dutton, Njobeh, Phoku, \& Yah, 2011; Makun, Gbodi, Akanya, Salako, \& Ogbadu, 2009). Studies from other parts of the world have also shown a prevalence of aflatoxigenic fungi (A. flavus) in rice crops (Reiter, Vouk, Bohm, \& Razzazi-Fazeli, 2010; Zuoxin, Junxia, \& Jiujiang, 2006). The presence of these fungal species was an indication of possible mycotoxin occurrence as some of these fungal species produce major mycotoxins (Sweeney \& Dobson, 1998). Some examples are A. flavus and A. parasiticus, which produce aflatoxins and are reportedly 
principal producers of aflatoxins in rice (Makun, Gbodi, Akanya, Salako, \& Ogbadu, 2009; Reiter, Vouk, Bohm, \& Razzazi-Fazeli, 2010; Zuoxin, Junxia, \& Jiujiang, 2006).

The study showed the same fungal genera occurring in food commodities from the two collection areas at almost the same incidence rate. The figures showed minimal contamination of some food commodities by Cladosporium, Rhizopus and Alternaria species from both collection areas which could be explained by the fact that these fungal genera are less occurring in the environment compared to other genera of the filamentous fungi family. It is usually common practice to find inappropriate food storage houses in Nigeria which are sometimes not properly ventilated and cleaned, since a higher population of farmers practice subsistence farming (Akande, 2010). These inappropriate storage practices could contribute or favour fungal growth on food commodities. The mode of transportation of these food commodities could also be a contributing factor to further contamination by these fungi species since most of the food commodities are not usually transported properly due to inadequate finances. The occurrence of these filamentous fungi species in the food commodities is a significance of the possible health risks consumers of the food commodities are exposed to. This is because of the negative health effects of metabolites of these filamentous fungi species which include immune suppressive, carcinogenic, mutagenic, teratogenic and genotoxic effects (Hussein \& Brasel, 2001; Richard, 2007). Also, contamination of these food commodities by filamentous fungi could result in reduction of food quality.

\section{Conclusion}

This study showed an almost equal distribution in fungal populations between food commodities collected from stores and markets because of the little difference in fungal populations from the two areas. We were able to determine the degree of contamination and prevalence of a wide range of filamentous fungal species in these food commodities from the south-western and south-eastern parts of Nigeria. The novelty of the study was determining a wide range of fungal populations contaminating some Nigerian food commodities especially cocoa and cocoa-based powder beverages. The presence of these fungal species is a reason for concern because most of the species isolated are producers of mycotoxins which have harmful health effects.

\section{Acknowledgements}

The authors wish to acknowledge the following institutions- University of Johannesburg and North-West University for the privilege to carry out this study and support to publish the findings.

\section{Conflict of Interest}

The authors declare that there is no conflict of interest.

\section{References}

Adejumo, T. O., Hettwer, U., \& Karlovsky, P. (2007). Survey of maize from south-western Nigeria for zearalenone, $\alpha$ - and $\beta$-zearalenols, fumonisin B1 and enniatins produced by Fusarium species. Food Additives and Contaminants, 24, 993-1000. http://dx.doi.org/10.1080/02652030701317285

Akande, T. (2010). An overview of the Nigerian rice economy.

Amézqueta, S., González-Peñas, E., Murillo, M., \& López de Cerain, A. (2005). Occurrence of ochratoxin A in cocoa beans: Effect of shelling. Food Additives \& Contaminants, 22(6), 590-596. http://dx.doi.org/10.1080/02652030500130160

Ardhana, M. M., \& Fleet, G. H. (2003). The microbial ecology of cocoa bean fermentations in Indonesia. $\begin{array}{lllll}\text { International Journal of Food } & \text { Microbiology, } & 86(1-2), & 87-99 .\end{array}$ http://dx.doi.org/10.1016/S0168-1605(03)00081-3

Atehnkeng, J., Ojiambo, P. S., Donner, M., Ikotun, T., Sikora, R. A., Cotty, P. J., \& Bandyopadhyay, R. (2008). Distribution and toxigenicity of Aspergillus species isolated from maize kernels from three agro-ecological zones in Nigeria. International Journal of Food Microbiology, 122(1-2), 74-84. http://dx.doi.org/10.1016/j.ijfoodmicro.2007.11.062

Borgemeister, C., Adda, C., Sétamou, M., Hell, K., Djomamou, B., Markham, R. H., \& Cardwell, K. F. (1998). Timing of harvest in maize: effects on post harvest losses due to insects and fungi in central Benin, with particular reference to Prostephanus truncatus (Horn) (Coleoptera: Bostrichidae). Agriculture, Ecosystems \& Environment, 69(3), 233-242. http://dx.doi.org/10.1016/S0167-8809(98)00109-1

Brera, C., Debegnach, F., De Santis, B., Iafrate, E., Pannunzi, E., Berdini, C., ... Miraglia, M. (2011). Ochratoxin A in cocoa and chocolate products from the Italian market: Occurrence and exposure assessment. Food Control, 22(10), 1663-1667. http://dx.doi.org/10.1016/j.foodcont.2011.03.026 
Chilaka, C. A., De Kock, S., Phoku, J. Z., Mwanza, M., Egbuta, M. A., \& Dutton, M. F. (2012). Fungal and mycotoxin contamination of South African commercial maize. Food, Agriculture and Environment, 10(2), 296-303.

Chu, F. S., \& Li, G. Y. (1994). Simultaneous occurrence of fumonisin B1 and other mycotoxins in moldy corn collected from the People's Republic of China in regions with high incidence of esophageal cancer. Applied and Environmental Microbiology, 60, 847-852.

Cocoa-growing. Retrieved January, 2012.

Cocoastory. Production process. Retrieved July, 2011.

Copetti, M. V., Iamanaka, B. T., Pereira, J. L., Fungaro, M. H., \& Taniwaki, M. H. (2011). Aflatoxigenic fungi and aflatoxin in cocoa. International Journal of Food Microbiology, 148(2), 141-144. http://dx.doi.org/10.1016/j.ijfoodmicro.2011.05.020

Copetti, M. V., Pereira, J. L., Iamanaka, B. T., Pitt, J. I., \& Taniwaki, M. H. (2010). Ochratoxigenic fungi and ochratoxin A in cocoa during farm processing. International Journal of Food Microbiology, 143(1-2), 67-70. http://dx.doi.org/10.1016/j.ijfoodmicro.2010.07.031

de Magalhães, J. T., Sodré, G. A., Viscogliosi, H., \& Grenier-Loustalot, M.-F. (2011). Occurrence of Ochratoxin A in Brazilian cocoa beans. Food Control, 22(5), 744-748. http://dx.doi.org/10.1016/j.foodcont.2010.11.006

Dutton, M. F. (1996). Fumonisins, mycotoxins of increasing importance: Their nature and their effects. Pharmacology \& Therapeutics, 70(2), 137-161. http://dx.doi.org/10.1016/0163-7258(96)00006-X

Dutton, M. F. (2003). Mycotoxin research in South Africa Advances in Applied Microbiology (Volume 53, pp. 213-241). Academic Press.

Fandohan, P., Gnonlonfin, B., Hell, K., Marasas, W. F. O., \& Wingfield, M. J. (2005). Natural occurrence of Fusarium and subsequent fumonisin contamination in preharvest and stored maize in Benin, West Africa. International Journal of Food Microbiology, $\quad 99(2), \quad$ 173-183. http://dx.doi.org/10.1016/j.ijfoodmicro.2004.08.012

Fassatiova, O. (1986). Moulds and filamentous fungi in technical microbiology. Elsevier Science, 22, $224-233$.

Gołofit-Szymczak, M., \& Górny, R. L. (2010). Bacterial and fungal aerosols in air-conditioned office buildings in Warsaw, Poland-The winter season. International Journal of Occupational Safety and Ergonomics, 16(4), 465-476.

Hussein, H. S., \& Brasel, J. M. (2001). Toxicity, metabolism, and impact of mycotoxins on humans and animals. Toxicology, 167(2), 101-134. http://dx.doi.org/10.1016/S0300-483X(01)00471-1

IARC. (2002). [Traditional herbal medicines, some mycotoxins, naphthalene and styrene. Monographs on the evaluation of carcinogenic risks to humans].

IARC. (2012). [Aflatoxins].

Jonathan, S. G., \& Esho, E. O. (2010). Fungi and aflatoxin detection in two stored oyster mushrooms (Pleurotus ostreatus and Pleurotus pulmonarius) from Nigeria. Electronic Journal of Environmental, Agricultural and Food Chemistry, 9(11), 1722-1730.

Juliano, B. O. (2003). Rice. In Caballero, B. (Ed.), Encyclopedia of Food Sciences and Nutrition (Second Edition) (pp. 4995-5001). Oxford: Academic Press. http://dx.doi.org/10.1016/B0-12-227055-X/01025-7

Klein, D. A., \& Paschke, M. W. (2004). Filamentous Fungi: the Indeterminate Lifestyle and Microbial Ecology. Microbial Ecology, 47(3), 224-235. http://dx.doi.org/10.1007/s00248-003-1037-4

Klich, M. A. (2002). Introduction; economic and medical importance of Aspergillus. Identification of common Aspergillus species (pp. 1-16). The Netherlands: Centraalbureau voor Schimmelculture, Utrecht.

Kumar, V., Basu, M. S., \& Rajendran, T. P. (2008). Mycotoxin research and mycoflora in some commercially important agricultural commodities. Crop Protection, $27, \quad 891-905$. http://dx.doi.org/10.1016/j.cropro.2007.12.011

Makun, H. A., Anjorin, S. T., Moronfoye, B., Adejo, F. O., Afolabi, O. A., Fagbayibo, G., ... Surajudeen, A. A. (2010). Fungal and aflatoxin contamination of some human food commodities in Nigeria. African Journal of Food Science, 4(4), 127-135. 
Makun, H. A., Dutton, M. F., Njobeh, P. B., Phoku, J. Z., \& Yah, C. S. (2011). Incidence, phylogeny and mycotoxigenic potentials of fungi isolated from rice in Niger State, Nigeria. Journal of Food Safety, 31(3), 334-349.

Makun, H. A., Gbodi, T. A., Akanya, O. H., Salako, A. E., \& Ogbadu, H. G. (2009). Health implications of toxigenic fungi found in two Nigerian staples: guinea corn and rice. African Journal of Food Science, 3(9), 250-256.

Marasas, W. F. O. (2001). Discovery and occurrence of the fumonisins: A historical perspective. Environmental Health Perspectives, 109, 239-243. http://dx.doi.org/10.1289/ehp.01109s2239

Meerdink, G. L. (2002). Mycotoxins. Clinical Techniques in Equine Practice, 1, 89-93. http://dx.doi.org/10.1053/ctep.2002.34240

Mounjouenpou, P., Gueule, D., Fontana-Tachon, A., Guyot, B., Tondje, P. R., \& Guiraud, J.-P. (2008). Filamentous fungi producing ochratoxin a during cocoa processing in Cameroon. International Journal of Food Microbiology, 121(2), 234-241. http://dx.doi.org/10.1016/j.ijfoodmicro.2007.11.017

Muri, S. D., van der Voet, H., Boon, P. E., van Klaveren, J. D., \& Brüschweiler, B. J. (2009). Comparison of human health risks resulting from exposure to fungicides and mycotoxins via food. Food and Chemical Toxicology, 47(12), 2963-2974. http://dx.doi.org/10.1016/j.fct.2009.03.035

Njobeh, P. B., Dutton, M. F., Koch, S. H., Chuturgoon, A., Stoev, S., \& Seifert, K. (2009). Contamination with storage fungi of human food from Cameroon. International Journal of Food Microbiology, 135(3), 193-198. http://dx.doi.org/10.1016/j.ijfoodmicro.2009.08.001

O'Donnell, K., \& Cigelnik, E. (1997). Two divergent intragenomic rDNA ITS2 types within a monophyletic lineage of the fungus Fusarium are nonorthologous. Molecular Phylogenetics and Evolution, 7(1), 103-116. http://dx.doi.org/10.1006/mpev.1996.0376

Oyetunji, T. O. (2006). Mycological evaluation of a ground cocoa-based beverage. African Journal of Biotechnology, 5(22), 2073-2076.

Petzinger, E., \& Weidenbach, A. (2002). Mycotoxins in the food chain: the role of ochratoxins. Livestock Production Science, 76(3), 245-250. http://dx.doi.org/10.1016/S0301-6226(02)00124-0

Pitt, J. I., \& Hocking, A. D. (1997). Fungi and mycotoxins in foods. In Orchard, A. E. (Ed.), Fungi of Australia, vol.1B, Introduction Fungi in the environment (pp. 315-342). Canberra, Australia: Austr. Boil. Res. Study.

Pitt, J. I., \& Hocking, A. D. (1997). Primary keys and miscellaneous fungi Fungi and food spoilage (2nd ed., pp. 59-171). London, Weinheim, New York, Tokyo, Melbourne, Madras: Blackie Academic and Professional. http://dx.doi.org/10.1007/978-1-4615-6391-4

Reiter, E., Zentek, J., \& Razzazi, E. (2009). Review on sample preparation strategies and methods used for the analysis of aflatoxins in food and feed. Molecular Nutrition \& Food Research, 53(4), 508-524. http://dx.doi.org/10.1002/mnfr.200800145

Reiter, E. V., Vouk, F., Bohm, J., \& Razzazi-Fazeli, E. (2010). Aflatoxins in rice- A limited survey of products marketed in Austria. Food Control, 21(7), 988-991. http://dx.doi.org/10.1016/j.foodcont.2009.12.014

Richard, J. L. (2007). Some major mycotoxins and their mycotoxicoses-An overview. International Journal of Food Microbiology, 119(1-2), 3-10. http://dx.doi.org/10.1016/j.ijfoodmicro.2007.07.019

Sánchez-Hervás, M., Gil, J. V., Bisbal, F., Ramón, D., \& Martínez-Culebras, P. V. (2008). Mycobiota and mycotoxin producing fungi from cocoa beans. International Journal of Food Microbiology, 125(3), 336-340. http://dx.doi.org/10.1016/j.ijfoodmicro.2008.04.021

Sweeney, M. J., \& Dobson, A. D. (1998). Mycotoxin production by Aspergillus, Fusarium and Penicillium species. International Journal of Food Microbiology, 43, 141-158. http://dx.doi.org/10.1016/S0168-1605(98)00112-3

Sydenham, E. W., Thiel, P. G., Marasas, W. F. O., Shephard, G. S., van Schalkwyk, D. J., \& Koch, K. R. (1990). Natural occurrence of some Fusarium mycotoxins in corn from low and high oesophageal cancer prevalence areas of the Transkei, Southern Africa. Journal of Agriculture and Food Chemistry, 38, 1900-1903. http://dx.doi.org/10.1021/jf00100a004 
Turner, P., Sylla, A., Gong, Y., Diallo, M., Sutcliffe, A., Hall, A., \& Wild, C. (2005). Reduction of exposure to carcinogenic aflatoxins by post-harvest intervention measures in West Africa: a community-based intervention study. Lancet, 365, 1950-1959. http://dx.doi.org/10.1016/S0140-6736(05)66661-5

Usha, C. M., Patkar, K. L., Shetty, H. S., Kennedy, R., \& Lacey, J. (1993). Fungal colonization and mycotoxin contamination of developing rice grain. Mycological Research, 97(7), 795-798. http://dx.doi.org/10.1016/S0953-7562(09)81152-0

Wagacha, J. M., \& Muthomi, J. W. (2008). Mycotoxin problem in Africa: Current status, implications to food safety and health and possible management strategies. International Journal of Food Microbiology, 124(1), 1-12. http://dx.doi.org/10.1016/j.ijfoodmicro.2008.01.008

Zuoxin, L., Junxia, G., \& Jiujiang, Y. (2006). Aflatoxins in stored maize and rice grains in Liaoning Province, China. Stored Products Research, 42, 468-479. http://dx.doi.org/10.1016/j.jspr.2005.09.003

\section{Copyrights}

Copyright for this article is retained by the author(s), with first publication rights granted to the journal.

This is an open-access article distributed under the terms and conditions of the Creative Commons Attribution license (http://creativecommons.org/licenses/by/3.0/). 